\title{
STUDI POTENSI PEMBANGKIT LISTRIK TENAGA SAMPAH (PLTSa) PADA TEMPAT PEMBUANGAN AKHIR (TPA) MAKBON KOTA SORONG
}

\author{
Serli Liling Allo ${ }^{1}$, Herryanus Widjasena ${ }^{2}$ \\ ${ }^{1}$ Teknik Elektro, Politeknik Katolik Saint Paul, Sorong \\ ${ }^{2}$ Teknik Elektro, Politeknik Katolik Saint Paul, Sorong \\ ${ }^{1}$ serlililingallo@gmail.com, ${ }^{2} \underline{\text { herryfr@@gmail.com }}$
}

\begin{abstract}
Abstrak
Tempat pembuangan akhir (TPA) mengemisikan Landfill Gas (LFG) yang mengandung paling banyak gas metana dan karbondioksida. Gas metana memiliki efek pemanasan beberapa kali lebih kuat dalam menyebabkan pemanasan bumi dibandingkan dengan $\mathrm{CO}_{2}$. Oleh karena itu pemanfaatan gas metana TPA sebagai bahan bakar pembangkit listrik telah menjadi target negara-negara berkembang untuk mengurangi green house gas emissions (GHGs). Sebelum membangun Pembangkit Listrik Tenaga Sampah (PLTSa) di sebuah TPA dibutuhkan serangkaian studi untuk menentukan apakah PLTSa layak dibangun di TPA tersebut, salah satunya adalah mengetahui jumlah LFG dari TPA untuk menghitung potensi energi listrik yang dapat dihasilkan. Tujuan dari penelitian ini adalah mengetahui jumlah LFG yang dihasilkan oleh TPA Makbon Kota Sorong dan selanjutnya menghitung potensi PLTSa berdasarkan kandungan gas metana dalam LFG. Tahapan penelitian dimulai dari pengumpulan data kuantitatif berupa jumlah ton sampah yang masuk ke TPA setiap tahun, ukuran TPA, dan jumlah penduduk. Untuk estimasi LFG digunakan perangkat lunak LandGEM-v302 yang diunduh dari website US Environmental Protection Agency. Sedangkan untuk estimasi potensi energi listrik digunakan rumus. Dari hasil penelitian, TPA Makbon Kota Sorong model sanitary landfill menghasilkan emisi maksimal gas metana sebesar $7,321 \times 10^{5} \mathrm{~m}^{3}$ pada tahun 2035 jika diasumsikan tahun 2020 sudah mulai menerima sampah. Berdasarkan hasil penghitungan dengan menggunakan rumus diperoleh potensi energi listrik maksimal yang dihasilkan $1,685 \times 10^{6} \mathrm{kWh}$.
\end{abstract}

Kata kunci : energi terbarukan, PLTSa, LFG, metana, Landgem-v302

\section{PENDAHULUAN}

\subsection{Latar Belakang}

Seiring dengan bertambahnya jumlah penduduk maka kebutuhan akan energi listrik juga semakin meningkat. Di Indonesia sampai saat ini, bahan bakar fosil masih merupakan sumber energi utama dalam pembangkitan energi listrik padahal cadangan bahan bakar fosil di dalam perut bumi semakin berkurang.

Oleh karena itu perlu dilakukan upaya untuk menekan ketergantungan terhadap energi bahan bakar fosil dengan menggunakan sumber energi terbarukan (renewable energy). Salah satu sumber energi terbarukan adalah sampah.

Tempat pembuangan akhir (TPA) mengandung sampah organik yang dapat mengemisikan LFG (Landfill Gas) yang dihasilkan secara kontinyu oleh mikroba pada keadaan anaerob [1]. LFG mengandung paling banyak gas metana dan karbondioksida, dimana kedua gas ini merupakan gas rumah kaca, selain itu adanya gas metana di TPA dapat menyebabkan terjadinya ledakan [2]. 
Pemanfaatan gas metana sebagai bahan bakar pembangkit listrik yang dihasilkan oleh TPA telah menjadi target negara-negara berkembang untuk mengurangi green house gas emissions (GHGs) [3].

Sebelum membangun Pembangkit Listrik Tenaga Sampah (PLTSa) dengan memanfaatkan gas metana, dibutuhkan serangkaian studi untuk menentukan apakah PLTSa layak dibangun di TPA tersebut. Langkah awal adalah mengetahui jumlah LFG dari TPA untuk menghitung potensi energi listrik yang bisa dihasilkan. Hal ini melatarbelakangi peneliti untuk mengambil judul penelitian, "Studi Potensi Pembangkit Listrik Tenaga Sampah (PLTSa) pada Tempat Pembuangan Akhir (TPA) Makbon Kota Sorong ”

\subsection{Tujuan Penelitian}

Tujuan dari penelitian ini adalah:

1. Mengetahui jumlah LFG yang dihasilkan oleh TPA Makbon Kota Sorong.

2. Menghitung potensi PLTSa dari LFG yang dihasilkan.

\subsection{Rumusan Masalah}

Dalam penelitian ini dirumuskan masalah sebagai berikut:

1. Bagaimana cara menghitung LFG yang dihasilkan oleh TPA.

2. Bagaimana cara menghitung besar energi listrik berdasarkan kandungan LFG.

\subsection{Pembatasan Masalah}

Dalam penelitian ini penulis membatasi permasalahan pada:

1. Studi potensi pembangkit listrik tenaga sampah berlokasi di TPA Makbon kota Sorong.

2. Penentuan LFG TPA Makbon kota Sorong menggunakan program aplikasi LandGEM-v302.

\section{DASAR TEORI}

\subsection{Sampah}

Menurut Kamus Besar Bahasa Indonesia (KBBI) sampah adalah barang atau benda yang dibuang karena tidak terpakai lagi.

Berdasarkan sifatnya sampah kota dapat dibagi menjadi dua yaitu :

1) Sampah organik adalah sampah yang mudah terdegradasi sehingga mudah terurai. Contohnya: sampah sayuran, daun-daunan, bagian tubuh hewan, sisa makanan, kertas, kayu dan lain-lain.

2) Sampah anorganik adalah sampah yang sulit terdegradasi sehingga sulit terurai. Contohnya: plastik, kaca, logam, kaleng dan lain-lain. [4]

\subsection{LFG (Landfill Gas)}

LFG adalah produk sampingan alami dari dekomposisi sampah di tempat pembuangan sampah. Secara ilmiah, biogas yang dihasilkan dari sampah organik adalah gas yang mudah terbakar (flammable). Gas ini dihasilkan dari proses fermentasi bahan-bahan organik oleh bakteri anaerob (bakteri yang hidup dalam kondisi tanpa udara). Umumnya, semua jenis bahan organik bisa diproses untuk menghasilkan biogas. Tetapi hanya bahan organik homogen, baik padat maupun cair yang cocok untuk sistem biogas sederhana. Bila sampah-sampah organik tersebut membusuk, akan dihasilkan gas metana $\left(\mathrm{CH}_{4}\right)$ dan karbondioksida $(\mathrm{CO} 2)$. Gas metana adalah gas yang sangat berbahaya dan memiliki efek pemanasan beberapa kali lebih kuat dalam menyebabkan pemanasan bumi dibandingkan dengan $\mathrm{CO}_{2}$. Metana dikenal sebagai gas rumah kaca yang memiliki 23 kali dampak pemanasan global yang lebih besar dari pada karbon dioksida.Dengan memanfaatkan $\mathrm{CH}_{4}$ yang sebagai bahan bakar maka dampak negatif gas metana dapat dikurangi. Secara umum komposisi biogas dapat dilihat pada Tabel 2.1 berikut ini [4] : 
JELC Vol. 5 No. 2

\section{Jurnal Elektro Luceat [November] [2019]}

Tabel 2.1. Komposisi Biogas

\begin{tabular}{|l|l|}
\hline Komponen & Persentase (\% Volume) \\
\hline Metana $\left(\mathrm{CH}_{4}\right)$ & $55-75$ \\
\hline Karbon dioksida $\left(\mathrm{CO}_{2}\right)$ & $25-45$ \\
\hline Nitrogen $\left(\mathrm{N}_{2}\right)$ & $0-0.3$ \\
\hline Hidrogen $\left(\mathrm{H}_{2}\right)$ & $1-5$ \\
\hline Hidrogen $\mathrm{Sulfida}\left(\mathrm{H}_{2} \mathrm{~S}\right)$ & $0-3$ \\
\hline Oksigen $\left(\mathrm{O}_{2}\right)$ & $0,1-0,5$ \\
\hline
\end{tabular}

Dengan memperhitungkan komposisinya, maka landfill gas bisa digunakan untuk pemasok energi bagi pembangkit tenaga listrik karena mengandung $55-75 \%$ metana, dimana metana adalah gas yang mudah terbakar.

\subsection{Pembangkit Listrik Tenaga Sampah (PLTSa)}

Pembangkit listrik tenaga sampah adalah pembangkit listrik thermal dengan uap supercritical steam dan berbahan bakar sampah atau gas methana. Sampah dibakar menghasilkan panas yang memanaskan uap pada boiler steam supercritical. Uap kompresi tinggi kemudian menggerakkan turbin uap dan flywhell yang tersambung pada generator dinamo dengan perantara gear transmisi atau transmisi otomatis sehingga menghasilkan listrik.

Pemanfaatan gas dari sampah untuk pembangkit listrik dengan teknologi fermentasi metana dilakukan dengan metode sanitary landfill yaitu memanfaatkan gas yang dihasilkan dari sampah (LFG). Sistem sanitary landfill dilakukan dengan cara memasukkan sampah ke dalam lubang, selanjutnya diratakan dan dipadatkan kemudian ditutup dengan tanah yang gembur, demikian seterusnya hingga membentuk lapisan-lapisan. Untuk memanfaatkan gas yang sudah terbentuk selanjutnya adalah memasang pipa-pipa penyalur untuk mengeluarkan gas. LFG yang dihasilkan dimanfaatkan sebagai bahan bakar. Skema pembangkit listrik tenaga sampah ditunjukkan pada gambar berikut : 


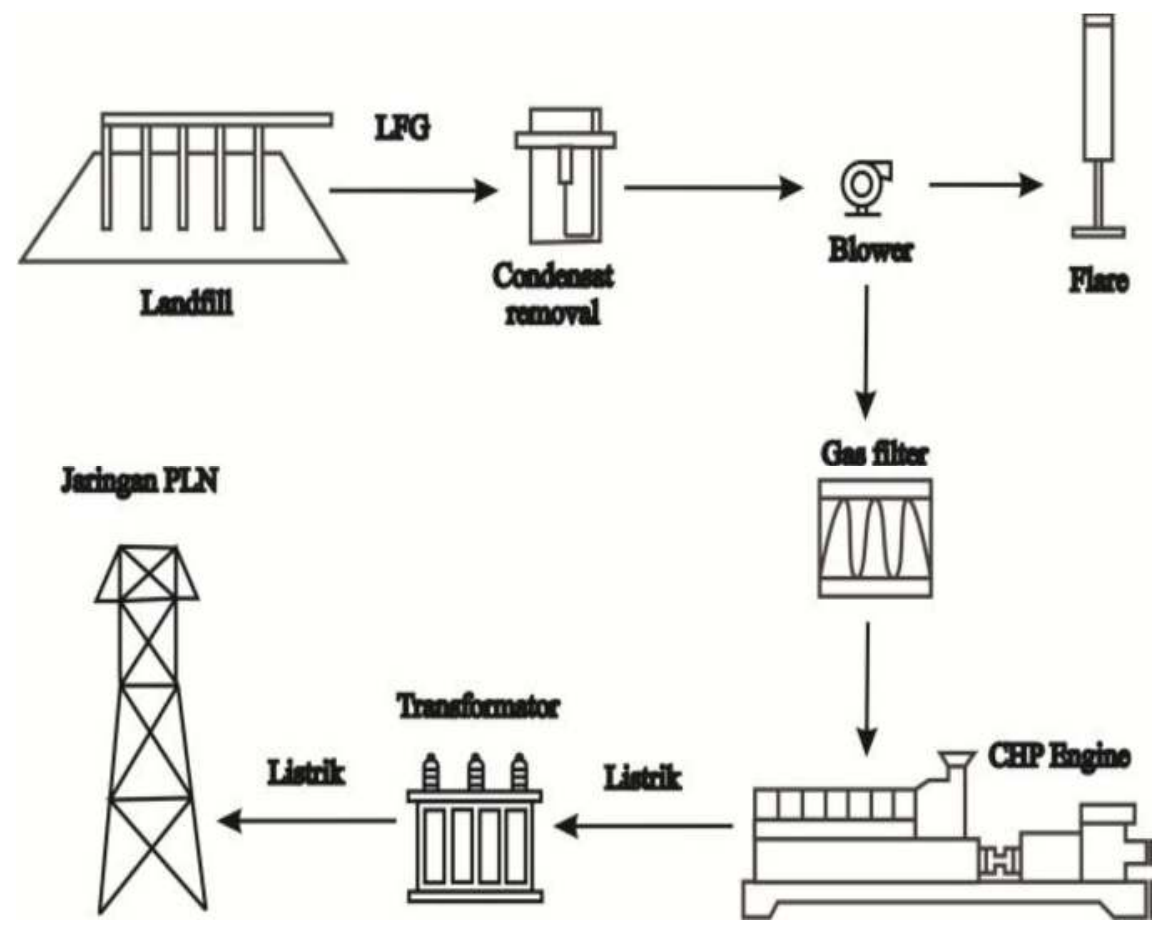

\section{Gambar 2.1 Skema pembangkit listrik tenaga sampah [5]}

\subsection{Landfill Gas Emissions Model (LandGEM)}

LandGEM (versi 3.02) adalah tool otomatis untuk mengestimasi tingkat emisi total LFG [6]. LandGEM dapat menggunakan data spesifik daerah yang diamati untuk mengestimasi tingkat emisi total gas atau menggunakan parameter default jika data spesifik tidak tersedia [7].

Model emisi metana LandGEM secara matematis menggunakan persamaan berikut [7]:

$Q_{C H 4}=\sum_{i=1}^{n} \sum_{j=0.1}^{1} K L o\left(\frac{M i}{10}\right) e^{-K t_{i j}}$

TPA akan memproduksi metana 6-12 bulan setelah menerima sampah kemudian meningkat sampai nilai maksimum dalam waktu yang tidak terlalu lama setelah tahun penutupan TPA dan akhirnya berangsur-angsur menurun di atas periode $30-50$ tahun [8]

dimana :

$\mathrm{Q}_{\mathrm{CH} 4}=$ emisi gas metana $\left(\mathrm{m}^{3} /\right.$ tahun $)$

$\mathrm{n} \quad=$ total periode waktu penimbunan sampah

$\mathrm{K} \quad=$ laju pertumbuhan metana (/tahun)

$\mathrm{L}_{\mathrm{o}} \quad=$ potensi produksi metana $\left(\mathrm{m}^{3} / \mathrm{ton}\right)$

Mi = Massa sampah yang diterima pada tahun $\mathrm{ke}-\mathrm{i}$ (ton) 
JELC Vol. 5 No. 2

$\frac{\text { Jurnal Elektro Luceat [November] [2019] }}{\mathrm{t}_{\mathrm{ij}} \quad \text { = waktu penimbunan sampah (tahun) }}$

\subsection{Potensi Energi Listrik}

Untuk menghitung potensi listrik yang dihasilkan dari landfill digunakan rumus [9] :

$$
E=\frac{L H V_{\text {methane }} \times 0,9 \times Q_{C H 4} \times \lambda \times \eta}{3.6}
$$

dimana,

E = energi listrik $(\mathrm{kWh} / \mathrm{tahun})$

$\mathrm{LHV}_{\text {methane }}=$ lower heating value of methane $=37.2 \mathrm{MJ} / \mathrm{m} 3$

$\mathrm{Q}_{\mathrm{CH} 4} \quad=$ tingkat emisi gas metana $\left(\mathrm{m}^{3} /\right.$ tahun $)$

$\lambda=$ efisiensi pengumpulan $=75 \%$

$\eta=$ efisiensi konversi listrik untuk mesin pembakaran dalam $=33 \%$

3,6 adalah faktor konversi dari MJ ke $\mathrm{kWh}$

\subsection{Pertumbuhan Penduduk}

Pertumbuhan penduduk adalah perubahan jumlah penduduk baik pertambahan maupun penurunannya. Faktor-faktor yang mempengaruhi pertumbuhan penduduk yaitu kelahiran (natalitas), kematian (mortalitas) dan perpindahan penduduk (migrasi). Kelahiran dan kematian dinamakan faktor alami, sedangkan perpindahan penduduk dinamakan faktor non alami.

Untuk pertambahan penduduk dinyatakan besarnya dengan angka, sedangkan pertumbuhan penduduk dinyatakan dengan persen (\%) yang umumnya dihitung tiap tahun. Untuk menghitung pertambahan penduduk digunakan rumus:

$$
\mathrm{P}=(\mathrm{L}-\mathrm{M})+(\mathrm{I}-\mathrm{E})
$$

Dimana:

$\mathrm{P}=$ Pertambahan Penduduk

$\mathrm{L}=\mathrm{Jumlah}$ kelahiran (natalitas) dalam satu tahun

$\mathrm{M}=$ Jumlah kematian (mortalitas) dalam satu tahun

I = Jumlah penduduk yang masuk (imigrasi)

$\mathrm{E}=$ Jumlah penduduk yang keluar (emigrasi)

Jumlah penduduk diwaktu yang akan datang dapat diketahui dengan cara membuat perkiraan atau proyeksi. Ada beberapa cara untuk membuat proyeksi penduduk yaitu: 


\section{a. Proyeksi penduduk aritmatik}

Dalam metode proyeksi ini, asumsinya adalah angka pertumbuhan penduduk dalam durasi waktu tertentu tetap konstan.

$$
\mathbf{P t}=\mathbf{P}+\mathbf{b . t}
$$

\section{Dimana :}

$\mathrm{Pt}=$ Proyeksi penduduk di masa depan

$\mathrm{P}=$ Penduduk tahun awal

$\mathrm{b}=$ angka pertumbuhan penduduk tahunan

$\mathrm{t}=$ waktu/periode

\section{b. Proyeksi penduduk geometrik}

Dalam metode proyeksi ini, pertumbuhan penduduk diasumsikan mengikuti deret geometri. Pertumbuhan diasumsikan konstan untuk jangka waktu tertentu [10].

Dimana :

$$
\mathbf{P}_{\mathbf{n}}=\mathbf{P}_{\mathbf{o}}(\mathbf{1}+\mathbf{r})^{\mathrm{n}}
$$

$\mathrm{P}_{\mathrm{n}}=$ Proyeksi penduduk tahun tertentu

$\mathrm{P}_{\mathrm{o}}=$ Penduduk awal tahun

1 = konstanta

$\mathrm{r}$ = angka pertumbuhan penduduk

$\mathrm{n}$ = rentang tahun

atau

$$
r=\left(\frac{P t}{P o}\right)^{\frac{1}{t}}-1
$$

\section{PEMBAHASAN}

\subsection{Profil Singkat TPA Makbon}

Wilayah TPA Makbon merupakan kawasan lereng-lereng yang curam dengan kedalaman mencapai 40 meter dengan luas 10 hektar. Metode pembuangan sampah di TPA Makbon adalah open dumping yaitu penumpukan sampah dilakukan di tempat terbuka. Metode open dumping memiliki kelemahan yaitu dapat menimbulkan pencemaran lingkungan yang berakibat buruk bagi kesehatan makhluk hidup yang berada di sekitar TPA. Oleh karena itu pemerintah kota Sorong telah merencanakan pengolahan sampah sanitary landfill dengan panjang kubangan $220 \mathrm{~m}$, lebar $110 \mathrm{~m}$, dan tinggi $8,2 \mathrm{~m}$.

Tipe TPA makbon adalah konvensional (normal) dengan komposisi sampah seperti pada Tabel 3.1 dengan jumlah sampah per tahun ditunjukkan oleh Tabel 3.2 sebagai berikut :

Tabel 3.1 Komposisi Sampah Kota Sorong

\begin{tabular}{|l|l|}
\hline Jenis Sampah & Persentase (\%) \\
\hline Organik & 51,37 \\
\hline
\end{tabular}


JELC Vol. 5 No. 2

\begin{tabular}{|c|c|}
\hline \multicolumn{2}{|c|}{ Jurnal Elektro Luceat [November] [2019] } \\
\hline Plastik & 22,26 \\
\hline Kertas/ karton & 17,12 \\
\hline Kaca/ botol & 6,84 \\
\hline Besi/ kaleng & 0,68 \\
\hline B3 & 1,71 \\
\hline
\end{tabular}

(Sumber : Dinas Kebersihan Kota Sorong)

Tabel 3.2 Jumlah Sampah Kota Sorong Tahun 2008 - 2011

\begin{tabular}{|l|l|}
\hline Tahun & Jumlah Sampah Masuk (Ton/Tahun) \\
\hline 2008 & 3750 \\
\hline 2009 & 3900 \\
\hline 2010 & 4050 \\
\hline 2011 & 4230 \\
\hline
\end{tabular}

(Sumber : Dinas Kebersihan Kota Sorong)

\subsection{Jumlah Penduduk kota Sorong}

Jumlah penduduk kota Sorong berdasarkan data Badan Pusat Statistik (BPS) kota Sorong ditunjukkan dalam tabel berikut :

Tabel 3.3 Jumlah Penduduk Kota Sorong Tahun 2010 - 2017

\begin{tabular}{|l|l|}
\hline Tahun & Jumlah Penduduk (Jiwa) \\
\hline 2010 & 190.625 \\
\hline 2011 & 198.990 \\
\hline 2012 & 205.584 \\
\hline 2013 & 211.840 \\
\hline 2014 & 218.799 \\
\hline 2015 & 225.588 \\
\hline 2016 & 232.833 \\
\hline 2017 & 239.815 \\
\hline
\end{tabular}

Berdasarkan tabel 3.3 di atas, dengan menggunakan rumus (2.6) dapat dihitung rata-rata laju pertumbuhan penduduk Kota Sorong per tahun adalah $3.335 \%$.

\subsection{Estimasi Kapasitas Sampah TPA Makbon} adalah :

Kapasitas sampah yang dapat ditampung oleh TPA Makbon untuk metode sanitary landfill

$\mathrm{V}=$ panjang $\mathrm{x}$ lebar $\mathrm{x}$ tinggi $\mathrm{x}$ tingkat pemadatan sampah

Berdasarkan Permen PU No. 13 tahun 2013, tingkat pemadatan sampah minimum $600 \mathrm{~kg} / \mathrm{m}^{3}$, dengan demikan :

$\mathrm{V}=220 \mathrm{~m} \times 110 \mathrm{~m} \times 8,2 \mathrm{~m} \times 600 \mathrm{~kg} / \mathrm{m}^{3}$

$\mathrm{V}=119.064 .000 \mathrm{~kg}=119.064$ ton 


\subsection{Estimasi Sampah Per Tahun}

Dari hasil wawancara dengan petugas di TPA, belum diketahui pasti kapan kubangan untuk sanitary landfill akan mulai digunakan. Oleh karena itu dalam penelitian ini diasumsikan TPA metode sanitary landfill mulai dioperasikan tahun 2020 dan ditutup saat sampah sudah memenuhi volume kubangan yaitu sekitar 119.064 ton. Jumlah sampah tiap tahun diestimasi dengan menggunakan metode regresi linier, dimana jumlah penduduk sebagai variable bebas (X) dan jumlah sampah sebagai variabel terikat (Y). Berdasarkan data jumlah penduduk dari website BPS Kota Sorong tahun 2010 - 2017 maka jumlah penduduk sejak tahun TPA dengan metode sanitary landfill dibuka (diasumsikan tahun 2020) hingga tahun TPA ditutup dapat dihitung dengan rumus proyeksi geometrik (rumus 2.5).

Hasil estimasi jumlah penduduk, jumlah sampah per tahun, dan akumulasi sampah ditunjukkan pada tabel berikut :

Tabel 3.4 Estimasi Jumlah Penduduk, Jumlah Sampah, dan Akumulasi Sampah TPA Sanitary Landfill Kota Sorong Tahun 2020 - 2035

\begin{tabular}{|l|l|r|r|r|}
\hline No & Tahun & \multicolumn{2}{l|}{$\begin{array}{l}\text { Jumlah Penduduk } \\
\text { (jiwa) }\end{array}$} & \multicolumn{2}{l|}{$\begin{array}{l}\text { Jumlah sampah } \\
\text { (ton) }\end{array}$} & \multicolumn{2}{l|}{$\begin{array}{l}\text { Akumulasi sampah } \\
\text { TPA (ton) }\end{array}$} \\
\hline 1 & 2020 & 264.632 & $6.012,51$ & $6.012,51$ \\
\hline 2 & 2021 & 273.456 & $6.241,95$ & $12.254,46$ \\
\hline 3 & 2022 & 282.575 & $6.479,05$ & $18.733,51$ \\
\hline 4 & 2023 & 291.998 & $6.724,04$ & $25.457,55$ \\
\hline 5 & 2024 & 301.736 & $6.977,21$ & $32.434,77$ \\
\hline 6 & 2025 & 311.797 & 7.238 .82 & $39.673,59$ \\
\hline 7 & 2026 & 322.195 & 7.509 .16 & $47.182,75$ \\
\hline 8 & 2027 & 332.939 & $7.788,51$ & $54.971,26$ \\
\hline 9 & 2028 & 344.042 & $8.077,18$ & $63.048,44$ \\
\hline 10 & 2029 & 355.515 & $8.375,47$ & $71.423,90$ \\
\hline 11 & 2030 & 367.370 & $8.683,71$ & $80.107,61$ \\
\hline 12 & 2031 & 379.621 & $9.002,22$ & $98.109,83$ \\
\hline 13 & 2032 & 392.280 & $9.331,36$ & $108.112,68$ \\
\hline 14 & 2033 & 405.361 & $9.671,48$ & $118.135,61$ \\
\hline 15 & 2034 & 418.879 & $10.022,94$ & $128.521,72$ \\
\hline 16 & 2035 & 432.847 & $10.386,11$ & \\
\hline
\end{tabular}

Dari tabel di atas, dengan melihat akumulasi sampah maka dapat diperkirakan TPA Makbon metode sanitary landfill dapat beroperasi sampai tahun 2034 jika dibuka tahun 2020 karena kapasitas sampah untuk kubangan sanitary landfill yang ada maksimal 119.064 ton.

\subsection{Estimasi LFG}

Hasil estimasi LFG menggunakan tool LandGEM versi 3.02 dengan parameter default dapat diihat pada gambar 4.1 dan tabel 4.5. Dapat dilihat bahwa satu tahun sejak mulai beroperasi landfill menghasilkan LFG dengan komposisi metana 49,80\%, karbondioksida sama dengan metana 49,80\%, dan NMOC 0,40\%. Komposisi ini sama untuk tahun-tahun berikutnya.

Gas metana yang dihasilkan tahun 2021 sebesar 4,997x $10^{4} \mathrm{~m}^{3}$ dan mencapai volume maksimal pada tahun 2035 yaitu $7,321 \times 10^{5} \mathrm{~m}^{3}$. Setelah tahun 2035 metana yang dihasilkan akan menurun. TPA akan terus mengemisikan gas metana sampai puluhan tahun dari tahun penutupan TPA, secara lengkap dapat dilihat pada lampiran. 
JELC Vol. 5 No. 2

Jurnal Elektro Luceat [November] [2019]

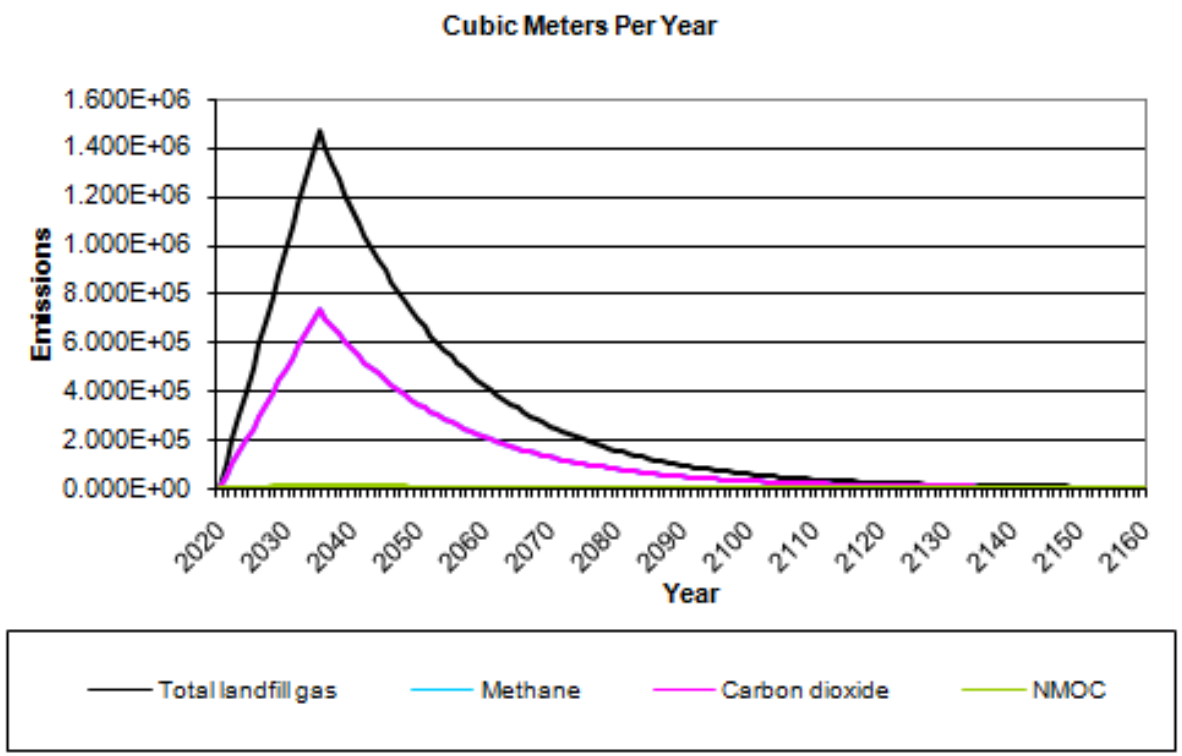

Gambar 3.1 Produksi LFG TPA Makbon metode sanitary landfill tahun 2020-2034 dengan LandGEM versi 3.02

Tabel 3.5 Estimasi LFG TPA Makbon Tahun 2021-2035

\begin{tabular}{|l|r|l|l|}
\hline Tahun & Metana $\left(\boldsymbol{m}^{3}\right.$ /year) & $\begin{array}{l}\text { Karbondioksioda } \\
\text { (m3/year) }\end{array}$ & $\begin{array}{l}\text { NMOC (Nonmethane } \\
\text { organic compound) } \\
\text { (m3/year) }\end{array}$ \\
\hline 2021 & $4.997 \mathrm{E}+04$ & $4.997 \mathrm{E}+04$ & $3.998 \mathrm{E}+02$ \\
\hline 2022 & $9.942 \mathrm{E}+04$ & $9.942 \mathrm{E}+04$ & $7.953 \mathrm{E}+02$ \\
\hline 2023 & $1.484 \mathrm{E}+05$ & $1.484 \mathrm{E}+05$ & $1.187 \mathrm{E}+03$ \\
\hline 2024 & $1.971 \mathrm{E}+05$ & $1.971 \mathrm{E}+05$ & $1.577 \mathrm{E}+03$ \\
\hline 2025 & $2.455 \mathrm{E}+05$ & $2.455 \mathrm{E}+05$ & $1.964 \mathrm{E}+03$ \\
\hline 2026 & $2.936 \mathrm{E}+05$ & $2.936 \mathrm{E}+05$ & $2.349 \mathrm{E}+03$ \\
\hline 2027 & $3.417 \mathrm{E}+05$ & $3.417 \mathrm{E}+05$ & $2.734 \mathrm{E}+03$ \\
\hline 2028 & $3.898 \mathrm{E}+05$ & $3.898 \mathrm{E}+05$ & $3.118 \mathrm{E}+03$ \\
\hline 2029 & $4.379 \mathrm{E}+05$ & $4.379 \mathrm{E}+05$ & $3.503 \mathrm{E}+03$ \\
\hline 2030 & $4.862 \mathrm{E}+05$ & $4.862 \mathrm{E}+05$ & $3.890 \mathrm{E}+03$ \\
\hline 2031 & $5.347 \mathrm{E}+05$ & $5.347 \mathrm{E}+05$ & $4.277 \mathrm{E}+03$ \\
\hline
\end{tabular}


JELC Vol. 5 No. 2

\begin{tabular}{|l|l|l|l|}
\hline \multicolumn{5}{c}{ Jurnal Elektro Luceat [November] [2019] } \\
\hline 2032 & $5.834 \mathrm{E}+05$ & $5.834 \mathrm{E}+05$ & $4.667 \mathrm{E}+03$ \\
\hline 2033 & $6.325 \mathrm{E}+05$ & $6.325 \mathrm{E}+05$ & $5.060 \mathrm{E}+03$ \\
\hline 2034 & $6.821 \mathrm{E}+05$ & $6.821 \mathrm{E}+05$ & $5.456 \mathrm{E}+03$ \\
\hline 2035 & $7.321 \mathrm{E}+05$ & $7.321 \mathrm{E}+05$ & $5.857 \mathrm{E}+03$ \\
\hline
\end{tabular}

\subsection{Estimasi Energi Listrik}

Dengan menggunakan rumus (2.2) energi listrik yang dihasilkan oleh PLTSa dari tahun 2021 - 2035 dapat dilihat pada tabel berikut:

Tabel 3.6 Estimasi Energi Listrik PLTSa TPA Makbon Tahun 2021 -2035

\begin{tabular}{|l|l|l|}
\hline Tahun & Metana (m3/year) & Energi Listrik (kWh) \\
\hline 2021 & $4.997 E+04$ & $1.150 \mathrm{E}+05$ \\
\hline 2022 & $9.942 E+04$ & $2.288 \mathrm{E}+05$ \\
\hline 2023 & $1.484 E+05$ & $3.416 \mathrm{E}+05$ \\
\hline 2024 & $1.971 E+05$ & $4.536 \mathrm{E}+05$ \\
\hline 2025 & $2.455 E+05$ & $5.650 \mathrm{E}+05$ \\
\hline 2026 & $2.936 E+05$ & $6.759 \mathrm{E}+05$ \\
\hline 2027 & $3.417 E+05$ & $7.866 \mathrm{E}+05$ \\
\hline 2028 & $3.898 E+05$ & $8.972 \mathrm{E}+05$ \\
\hline 2029 & $4.379 E+05$ & $1.008 \mathrm{E}+06$ \\
\hline 2030 & $4.862 E+05$ & $1.119 \mathrm{E}+06$ \\
\hline 2031 & $5.347 E+05$ & $1.231 \mathrm{E}+06$ \\
\hline 2032 & $5.834 E+05$ & $1.343 \mathrm{E}+06$ \\
\hline 2033 & $6.325 E+05$ & $1.456 \mathrm{E}+06$ \\
\hline 2034 & $6.821 E+05$ & $1.570 \mathrm{E}+06$ \\
\hline 2035 & $7.321 E+05$ & $1.685 \mathrm{E}+06$ \\
\hline
\end{tabular}

Berdasarkan tabel 3.6 di atas, energi listrik maksimal dapat diperoleh pada tahun 2035 yaitu sebesar $1,685 \times 10^{6} \mathrm{kWh}$. 


\section{KESIMPULAN}

Dari hasil penelitian dapat disimpulkan sebagai berikut :

1. TPA Makbon Kota Sorong model sanitary landfill dengan ukuran kubangan panjang $220 \mathrm{~m}$, lebar $110 \mathrm{~m}$, dan tinggi 8,2 $\mathrm{m}$ dapat beroperasi sekitar 14 tahun jika diasumsikan tahun 2020 sudah mulai menerima sampah.

2. Satu tahun sejak mulai beroperasi landfill sudah menghasilkan metana dan akan terus meningkat tiap tahun hingga mencapai maksimal. Setelah mencapai nilai maksimalnya, emisi gas metana akan berangsur-angsur turun dalam waktu puluhan tahun.

3. Emisi maksimal gas metana sebesar $7,321 \times 10^{5} \mathrm{~m}^{3}$ terjadi pada tahun 2035 , satu tahun setelah penutupan TPA.

4. Energi listrik maksimal yang dihasilkan landfill adalah $1,685 \times 10^{6} \mathrm{kWh}$.

5. Total energi listrik yang dihasilkan dari tahun $2021-2035$ adalah $13,48 \times 10^{6} \mathrm{kWh}$.

\section{DAFTAR PUSTAKA}

[1] Couth, R. C., Trois, S., Vaughan, J. 2011. Modelling of green houses gas emissions from municipal solid waste disposal in Africa. International Journal of Greenhouse Gas Control. 5, 1443-1453.

[2] Amini, A., Nematollahi, H., Banestani, N.M. 2017. Estimation and Modelling of Biogas Production in Rural Small Landfills (Case Study:Chaharmahaal and Bakhtiari and Yazd Rural Areas). Environmental Energy and Economic Research. 1 : 4, 383-392.

[3] Kalantarifard, A., Yang, G. S. 2012. Estimation of Methane Production by LANDGEM Simulation Model From Tanjung Langsat Municipal Solid Waste Landfill, Malaysia. International Journal of Science and Technology. 1 : 9, 481-487

[4] Destilia, A. , Pertiwi, M. B., Bahrin, D. 2012. Pengaruh Jenis Sampah, Komposisi Masukan dan Waktu Tinggal Terhadap Komposisi Biogas Dari Sampah Organik . Jurnal Teknik Kimia 18 : 1, 19

[5] Alan Nazlie Haq. 2012. Studi Potensi Pembangkit Listrik Listrik Tenaga Sampah di Kota Banjarmasin.

[6] Rodrigue, K. A., et all. 2018. Estimation of Methane Emission from Kossihouen Sanitary Landfill and Its Electricity Generation Potential. Journal of Power and Energy Engineering. 6, 22-31

[7] US EPA. 2005. Landfill Gas Emissions Model (LandGEM) Version 3.02 User's Guide. [Online] Tersedia di http://www.epa.gov/ttncatc1/dir1/landgem-v302-guide.pdf [diakses pada 1 Mei 2019

[8] Falzon, J. 1997. Landfill Gas: An Australian Perspective. Sixth International Landfill Symposium. Sardinia, Italy. 2, pp 487-496

[9] Ayodele, T.R., Ogunjuyigbe, A.S.O. and Alao, M.A. 2017. Life Cycle Assessment of Wasteto-Energy (WtE) Technologies for Electricity Generation Using Municipal Solid Waste in Nigeria. Applied Energy, 201, 200-218.

[10] https://www.rumusstatistik.com/2013/09/laju-pertumbuhan-penduduk-geometrik.html [diakses pada 10 Juni 2019] 